\title{
INCIDENCIAS DE LAS CONTRADICCIONES SOCIALES EN EL COMPORTAMIENTO DEL CONSUMIDOR TURÍSTICO DEL ECUADOR
}

Frank Lemoine- Quintero ${ }^{1 *}$, Norma Fernández Rodríguez ${ }^{2}$ y Lilia Villacis Zambrano ${ }^{3}$

${ }^{1,3}$ Universidad Laica Eloy Alfaro de Manabí, Bahía de Caráquez, Ecuador

${ }^{2}$ Universidad de Oriente, Santiago de Cuba, Cuba

*Autor de correspondencia: flemoine1964@gmail.com

Recibido Octubre 2020; Aceptado Diciembre 2020

\begin{abstract}
Resumen - El estudio tiene como objetivo de realizar un análisis de las contradicciones sociales que afectan el comportamiento del consumidor en el desarrollo de los destinos turísticos en Ecuador. Se realiza un estudio del estado del arte que aporte al acercamiento de la ciencia social y los factores que influyen en el comportamiento de los consumidores. La investigación es del tipo aplicada y descriptiva. Se empleó el muestreo aleatorio simple para seleccionar los elementos de la muestra utilizada en la encuesta. La población considerada fue el promedio de turistas que visitaron el destino en el 2015: 8048 y el tamaño de la muestra fue de 366. El método analítico descriptivo permitió reflexionar sobre los indicadores de satisfacción y su aporte al comportamiento de los consumidores turísticos desde la concepción de grado de satisfacción donde el $45 \%$ evaluaron el destino de muy bien, el motivo de viaje donde el 26\% lo realizo por ocio, vacaciones o recreo y el 35.1\% visitan centros históricos del país. Se realiza un estudio de los mercados emisores según histórico estadísticos del 2014 al 2017 donde se denota una variación en los indicies de turistas al país. El análisis de las contradicciones sociales en el proceso del comportamiento al consumidor permitió definir las causas que han afectado la gestión del destino desde el plano epistemológico, político, económico, cultural y ambiental. El estudio aporta que al adoptar un enfoque integrado teniendo presente las dimensiones económicas, sociales y ambientales se lograra una gestión del destino eficiente y eficaz.
\end{abstract}

Palabras clave: comportamiento al consumidor, contradicciones sociales, gestión, turismo, destino.

\section{INCIDENTS OF SOCIAL CONTRADICTIONS ON THE BEHAVIOR OF TOURIST CONSUMERS IN ECUADOR}

\begin{abstract}
The study aims to carry out an analysis of the social contradictions that affect consumer behavior in the development of tourist destinations in Ecuador. A study of the state of the art is carried out that contributes to the approach of social science and the factors that influence the behavior of consumers. The research is of the applied and descriptive type. Simple random sampling was used to select the elements of the sample used in the survey. The population considered was the average number of tourists who visited the destination in 2015: 8048 and the sample size was 366. The descriptive analytical method allowed us to reflect on the satisfaction indicators and their contribution to the behavior of tourist consumers from conception degree of satisfaction where $45 \%$ evaluated the
\end{abstract}


destination as very well, the reason for the trip where $26 \%$ did it for leisure, vacations or recreation and $35.1 \%$ visit historical centers of the country. A study of the issuing markets is carried out according to historical statistics from 2014 to 2017, which shows a variation in the rates of tourists to the country. The analysis of the social contradictions in the process of consumer behavior made it possible to define the causes that have affected the management of the destination from the epistemological, political, economic, cultural and environmental levels. The study provides that by adopting an integrated approach bearing in mind the economic, social and environmental dimensions, an efficient and effective destination management will be achieved.

Keywords: consumer behavior, social contradictions, management, tourism, destination.

\section{Introducción}

El El turismo hoy en día simboliza una de las actividades más representativa dentro de la economía de un país favoreciendo la generación de empleos e incidiendo en los indicadores del producto interno bruto además de contribuir a equilibrar la balanza de pagos, aumentando los ingresos públicos y fomentando la actividad empresarial, comercial y de servicios fundando impactos positivos a nivel de país o comunidad, Ecuador como país no está exento de esto.

Por lo que es importante considerar la gestión que ha venido desarrollando la Organización Mundial del Turismo (OMT, 1994) a partir de sus pronunciamientos en aras de atribuirle al turismo la relevancia e importancia que este tiene en bien de la humanidad. La generación de políticas vigentes y los protocolos que esta organización ha venido desarrollando tiene una relevancia desde su aporte a la globalización de los países en vista de incentivar el intercambio sociocultural, tecnológico, financiero y económico. Por esto es importante concebir la definición que esta organización otorga el turismo, manifestando que "el turismo comprende las actividades que realizan las personas durante sus viajes y estancias en lugares distintos a su entorno habitual, por un período de tiempo consecutivo inferior a un año, con fines de ocio, por negocios y otros” (p. 13).

Se debe reconocer que a partir del siglo XVI hasta mediados del siglo XIX existen los primeros pronunciamientos en bases al "turismo moderno", conocido bajo la denominación "Gran Tour" del que subsiguientemente se deriva el termino turismo. Es importante reflexionar que consistió en otorgar a los jóvenes de la nobleza y clase media inglesa a viajar con fines de perfeccionar e integrar instrucciones o conocimientos en temas de interés o cultural. (Rodriguez, 2011, p.52).

Estos movimientos se diferencian por su propósito de otros tipos de viajes originados por guerras, conquista, comercio, entre otros. El turismo reside en viajes y permanencias que realizan las personas en entornos diversos de su ambiente frecuente, concebido por diversión en su totalidad, propósito mercantil o profesional, salud y entre otros de acuerdo a sus deseos, necesidades o experiencias propias recibidas o transmitida a través de otras personas o por medios de comunicación. Se le otorga al turismo una de las industrias más importantes a nivel mundial por generar fuentes de ingresos altos y por impulsar dentro de la actividad mercantil el fortalecimiento de diferentes actividades económicas. 
El producto turístico es considerado como el conjunto de atributos tangibles e intangibles, que genera utilidades o beneficios al cliente y que a su vez este puede aceptar como satisfactorio de acuerdo a su percepción y sus expectativas, por lo que puede identificarse desde la conceptualización de Mármol \& Ojeda (2016) como "todo aquello que se pueda ofrecer a un mercado turístico para que se adquiera, se use, se consuma o se le preste atención, con el objetivo de satisfacer un deseo o necesidad" (p. 25).

Se debe argumentar que el progreso alcanzado por la actividad turística en los últimos años ha fructificado ideas referentes a desarrollar términos específicos que accedan a definir las disímiles actividades de acuerdo al sector. El producto turístico debe integrar todo aquel servicio de uso exclusivo de acuerdo a sus características, especificaciones, atributos y dimensiones que lo identifiquen. Tiene su principal insumo en los atractivos, en torno del cual giran una serie de elementos que permiten que se desarrolle la actividad turística en un espacio determinado.

El sector turístico en la actualidad ha experimentado una evolución marcada de la orientación del marketing, reconociendo que durante décadas su único objetivo era producir y vender. La conformación de paquetes turísticos estandarizados, de idéntica composición y venta masiva, generaba a las personas y fin común, olvidándose por completo de cubrir las expectativas de la muy diversa tipología de clientes (Campón, 2009, p. 21).

Estudios referentes al comportamiento del consumidor han mostrado el rol de este dentro de las empresas turísticas, donde se reconoce al consumidor como un individuo con fuerzas psicológica y emocionales capaces de desarrollar a nivel de sub consciente acciones que responden atribuir una conducta positiva o negativa a partir del contexto social y cultural de satisfacción o insatisfacción (Lemoine, Delgado, Carvajal, \& Alcívar, 2017, p.132).

Los sucesos telúricos ocurrido en Ecuador marcaron una nueva etapa para el turismo en el país, en el 2015 fue muy representativo los niveles de ingresos por conceptos turísticos ocupando la tercera fuente de ingreso dentro del sector económico a nivel nacional representando un crecimiento de un $2.9 \%$ en número de visitantes respecto al 2014.En 2016, los ingresos decrecieron en un 6,9 \% y la llegada de turistas en un 8,1 \% representando el 1,4\% del PIB, como resultado de los cambios generados en la economía nacional y los eventos telúricos que provocaron incertidumbres a nivel de este sector en el país. El 2017 representa un crecimiento con respecto al año anterior del $14 \%$ y debido a las estrategias asumida por el gobierno e involucrados en el sector turístico la actividad turística simbolizado el turismo el $16 \%$ del PIB y en el 2018 el PIB creció respecto al año anterior en un 1,7\% respectivamente mostrando un destino sostenible (Lemoine, Reyes, \& Valls, 2018, p. 141).

La Extensión de Bahía de Caráquez bajo los preceptos académicos busca a atribuirle a la sociedad profesionales capaces y actos de incidir a la solución que generan los impactos de la propia sociedad mediante la contribución de soluciones de conocimientos efectivos y eficaces para hacer de las actividades económicas las nuevas formas de tributo social y económico de las comunidades del sector. El departamento de investigación y vinculación buscan nuevas alternativas para atribuirle a las comunidades estrategias comunicativas, funcionales, de alianzas y de diversificación al sector turístico como una medida de sostenibilidad del turismo (Valls \& Lemoine, 2018, p. 121).

IPSA SCIENTIA - Vol. 5 No $1-2020$ 
En la actualidad la universidad trabaja desde sus proyectos investigativos vigentes buscar alternativas estratégicas para una gestión turística continua en bien desarrollo del sector turístico y de contribución al cambio de la matriz productiva, a partir de los siguientes problemas denotados en estudios realizados, los cuales se exponen a continuación:

- Bajos porcentajes de ocupación de la planta hotelera inciden en indicadores económicos del sector turístico de la zona

- Marcada estacionalidad de la demanda por deficiente uso del marketing experiencial

- Bajos ingresos por turista provocan falencia de la gestión de la calidad del servicio

- Escaso enfoque de marketing hacia el cliente incide en la calidad del servicio y la satisfacción de los turistas que frecuentan el destino turístico.

- Deficiente gestión comercial en los destinos turísticos de la zona provoca toma de decisiones no efectivas en la relación de gestión con los clientes.

Dentro de los inconvenientes del turismo expuesto anteriormente el que más afecta es el nivel de ocupación de planta hotelera está por debajo del 15\% de ocupación lo que denota un decrecimiento en los indicadores económico del destino. El objetivo de este trabajo esta direccionado a realizar un estudio de las contracciones sociales que afectan el comportamiento del consumidor a partir de preceptos de obras, bibliografías y artículos que tributan al desarrollo de los destinos turísticos en Ecuador. Se realizará una valoración desde el orden reflexivo para analizar las principales causas que afectan la gestión del turismo a nivel de país y de destino.

\section{Materiales y Métodos}

El Ministerio de Turismo (MINTUR, 2018) dentro de sus funciones elementales se faculta de fomentar el turismo en el Ecuador como destino único. Dentro de sus funciones esta incidir en el desarrollo social y económico de las comunidades, regiones y recintos del país con la finalidad de retribuir equitativamente el fortalecimiento de la actividad turística en todo el país. Busca generar nuevos emprendimientos desde el contexto turístico y a su vez la generación de nuevas fuentes empleo y el desarrollo de estrategias colaborativas para el desarrollo de la cadena productiva del país.

Es importante reconocer que en diciembre de 2017 se registró de llegada de turista al país representando un incremento del 30,3\% superior con relación a diciembre del año anterior al recibir un total de 171.926 turistas extranjeros que recorrieron los diversos destinos turísticos. Los gobiernos en tránsito reconociendo la importancia que la actividad genera económicamente buscan fuentes de financiamientos para proyectos innovadores como estrategias para fortalecer y posicionar la actividad turística en el mercado internacional.

Se parte del método analítico descriptivo. Se fundamenta en el trabajo reflexiones sociales por autores e investigadores que argumentan sobre las ciencias sociales y su aporte a la gestión comercial del destino turístico a nivel de país, cantones o sectores. Se enfatiza además sobre el acercamiento de las ciencias sociales y su aporte a la gestión del estado del arte que sustenta el análisis del objetivo planteado referente a las contradicciones de las ciencias sociales y sus implicaciones en el comportamiento de los consumidores.

IPSA SCIENTIA - Vol. 5 No $1-2020$ 
Para obtener los indicadores de satisfacción se aplicó a los turistas una encuesta elaborada con ese fin en la investigación. La población considerada fue el promedio de turistas que visitaron el destino en el 2015: 8048 turistas. El método de muestreo empleado fue el muestreo aleatorio simple.

A fin de determinar el tamaño de la muestra para la realización de las encuestas se utilizará fórmula siguiente (Gould, F. J., G. D. Eppen et al., 1993):

donde:

$$
n=\frac{P(1-P)}{\frac{E^{2}}{Z^{2}}+\frac{P(1-P)}{N}}
$$

$\mathrm{E}=$ Diferencia admisible en la proporción.

$\mathrm{Z}=$ Valor del grado de confianza en la tabla normal.

$\mathrm{P}=$ Proporción de la población.

$\mathrm{N}$ = Tamaño de la población.

$\mathrm{n}=$ Tamaño de la muestra

Al sustituir los datos en la ecuación 1, se obtiene el valor mostrado en la ecuación 2:

$$
\mathrm{n}=\frac{(1,96)^{2}(0,5)(0,5)(8048)}{8047^{*}(0,05)^{2}+(1,96)^{2}(0,5)(0,5)} \approx 366
$$

El tamaño de la muestra fue de 366 turistas.

Las encuestas fueron aplicadas por estudiantes pertenecientes al proyecto de investigación. Las encuestas fueron procesadas empleando el paquete de programas SPSS versión 22.

\section{Resultados y Discusión}

\section{Principales concepciones acerca de los consumidores}

Es importante concebir que el comportamiento del consumidor se deriva de la noción de marketing, siendo reconocida a finales de la década de 1950, a partir de los años 1970 se produce una ampliación del alcance del marketing en un doble sentido. Se sostienes que el crecimiento económico dio solución a las imperfecciones del mercado e, incluso, hay quien afirma que el marketing no sólo solucionará los problemas sociales, sino que "traerá también la paz mundial" (Lavidge, 1970).

Por consiguiente, es relevante reconocer argumentos de Kotler \& Armstrong (2007), Kotler \& Armstrong (2008) y Kotler \& Armstrong (2012), así como de la American Marketing Association (AMA) que ofrecen una nueva definición de marketing, como "el proceso de planificación y ejecución de la concepción, precio, comunicación y distribución de ideas, productos y servicios para crear intercambios que satisfagan a los individuos y a los objetivos de IPSA SCIENTIA - Vol. 5 No $1-2020$ 
la organización”. Estudios posteriores más actuales a la temática se han enfocado en la gestión del marketing turístico como un proceso de posicionamiento de un destino turístico en búsqueda de mejores alternativas económicas sostenibles para un destino turístico. (Lemoine, Villacís, Hernández, Zamora \& Montesdeoca, 2019, p. 112).

El progreso que ha tenido el marketing se manifiesta mediante las distintas definiciones que lo han llevado a nutrirse tales como: actividad, proceso, función, sistema, enfoque, disciplina e inclusive, en otro entorno como ciencia de gestión normativa en dependencia de su funcionabilidad y utilidad.

Referente al entorno lo conceptual tiene su explicación debido a las dimensiones del marketing principalmente al relacional con la finalidad de analizar y darle seguimiento de las necesidades del individuo y de las organizaciones para complementar sus expectativas. Escenario que de acuerdo a su desenvolvimiento incidirá de forma adecuada para generar resultados acordes a las exigencias de las empresas u organizaciones.

Se reconoce que las empresas cuentan hoy en día tienen la habilidad de reconocer los niveles de ventas de los productos o servicios a partir de información previa referentes a las necesidades específicas que iban a satisfacer en el consumidor. En la actualidad las empresas más exitosas del mundo han logrado un nivel de satisfacción representativo de los consumidores, convirtiendo a las empresas en servidores fieles a sus consumidores. Estas empresas han generado un enfoque para el consumidor, en donde han determinado en primer lugar qué quieren para poder innovar, diseñar, producir y comercializar productos o servicios con la más alta calidad y a precios razonables (Carvajal, Valls, Lemoine, \& Alcívar, 2017, p. 55).

Apoyados en criterios abordados por J. Paul Peter (2006), quien afirma que "El comportamiento del consumidor abarca los pensamientos y sentimientos que experimentan las personas, así como las acciones que emprenden, en los procesos de consumo" (p. 125).

De la anterior definición, observando su aporte desde la contribución social en estudio relacionado al tema investigativo es importante deducir que:

- Los sentimientos, pensamientos y acciones de cada consumidor se modifican a cada momento gracias a que su medio ambiente está también en constante movimiento, los ciclos de vida de los productos son más breves y las empresas se ven en la necesidad de revisar de forma constante sus estrategias de marketing (Carbache, Zambrano, \& Lemoine, 2020, p.32)

- Los sentimientos, pensamientos y acciones de los consumidores tienen importantes interacciones con su medio ambiente, proporcionando información a los mercadólogos sobre las preferencias de algunos productos o servicios y el porqué de esas preferencias el autor Lemoine (2018, p. 25) hace referencia a su estudio referente a la metódica para medir comportamientos de los consumidores en el sector hotelero. Ecuador, donde se enfatiza que el intercambio entre los seres humanos es algo inevitable, el comportamiento de los consumidores consiste en que las personas entreguen dinero a otras para obtener productos y servicios, que satisfagan necesidades (Lemoine, Carvajal, Zamora, \& Castellanos, 2018, p. 75). 
De esto se concluye que la tipología de los consumidores considerada por especialista en la temática no es estática, sino que cada sujeto puede variar su conducta dependiendo del entorno o momento en el cual se desempeñe o se encuentren ubicado. Sin descartar que los estilos de vida forman parte de una conducta de consumo de los consumidores que pueden identificarlo dentro de una tipología integrada por factores económicos sociales.

\section{Comportamiento del consumidor}

Desde este estudio es importante fundamentar que los consumidores en servicios turísticos en el periodo 2016/2019 estadísticamente según verificaciones se han mostrado de manera ascendente. A continuación, se mencionan tres elementos que han incidido de manera favorable en las cifras estadísticas del país, la primera es en la satisfacción de los visitantes, la segunda el motivo de viaje y la tercera los sitios más visitados. (MINTUR, 2017)

Estudios relacionados a la temática abordan del consumidor que el turismo desarrolla actitudes que se establecen en correspondencia con el destino turístico como producto; estas se transforman en emociones o en lo supuesto convirtiéndose en las expectativas antes del arribo al destino. Establecido en el destino electo, el turista vivencia una sucesión de rutinas que se convertirán en las experiencias y en la formación de criterios acerca del destino permitiendo de esta forma medir su oportuna complacencia con la decisión tomada. Permitiendo de esta forma conocer los niveles de satisfacción del consumidor turístico y su comportamiento dependiendo dela planificación de las actividades desarrollada en el destino, de las acciones por los que generan las ofertas y por los operadores del sistema como una fuente de oportunidades de mejora continua en la satisfacción del turista mediante la reconstrucción de la oferta del destino, ajustándola y alineándola a ese comportamiento (Ramírez, Otero \& Giraldo, 2014, p.67).

Considerar todos los elementos que inciden en el comportamiento del consumidor es importante para poder concebir un destino consolidado, para esto deben de existir las herramientas del marketing efectivas para ese destino específico o al menos que se adapte a las similitudes del destino o a las fuerzas actuantes del entorno, tomando en cuenta que el factor sociocultural ejerce un rol importante para impulsar cualquier actividad turística.

Desde la concepción de comportamiento de los consumidores asumimos que los turistas buscan satisfacer sus necesidades desde el concepto familiar que es el más representativo en el turismo emisor del país por el número de inmigrantes existentes y que deciden tomar sus vacaciones en unión de familiares y amigos, aunque es representativo los que los desarrollan por ocios o recreación sin dejar de reconocer los que asisten por negocios que puede ser una estrategia para desarrollar una nueva actividad turística en el país. A continuación, en la figura 1 se muestran resultados de una encuesta realizadas a turistas con la finalidad de reflejar las cifras más representativas del comportamiento de consumidores turísticos. 
Figura 1. Elementos de incidencia de comportamiento

\section{Grado de Satisfacción.}

Es notorio que los turistas se sienten satisfecho por los servicios recibido en el país, donde el $45 \%$ lo evalúa de muy bien y un $29 \%$ lo valora de bien, aunque un $20 \%$ no informa que deja en duda la actitud $\mathrm{y}$ es donde se deben de encaminar estrategias funcionales.

Motivo de viaje

El $30 \%$ del total visita a familiares y amigos, seguido por un $26 \%$ de visitantes que lo realizan por ocio, recreo o vacaciones y un $15 \%$ por negocios, siendo estos los pocos representativos.

Sitios más visitados.

La estadística refleja la ciudad de Quito donde resultó ser la más visitada, donde dentro de sus atractivos el más frecuentado es el centro histórico (35.1\%) denotando en el turista interés por atractivos culturales, su segunda opción es el teleférico que represento el $11.5 \%$, seguido por el $9.2 \%$ que es el atractivo del Panecillo que es un centro cultural religioso.
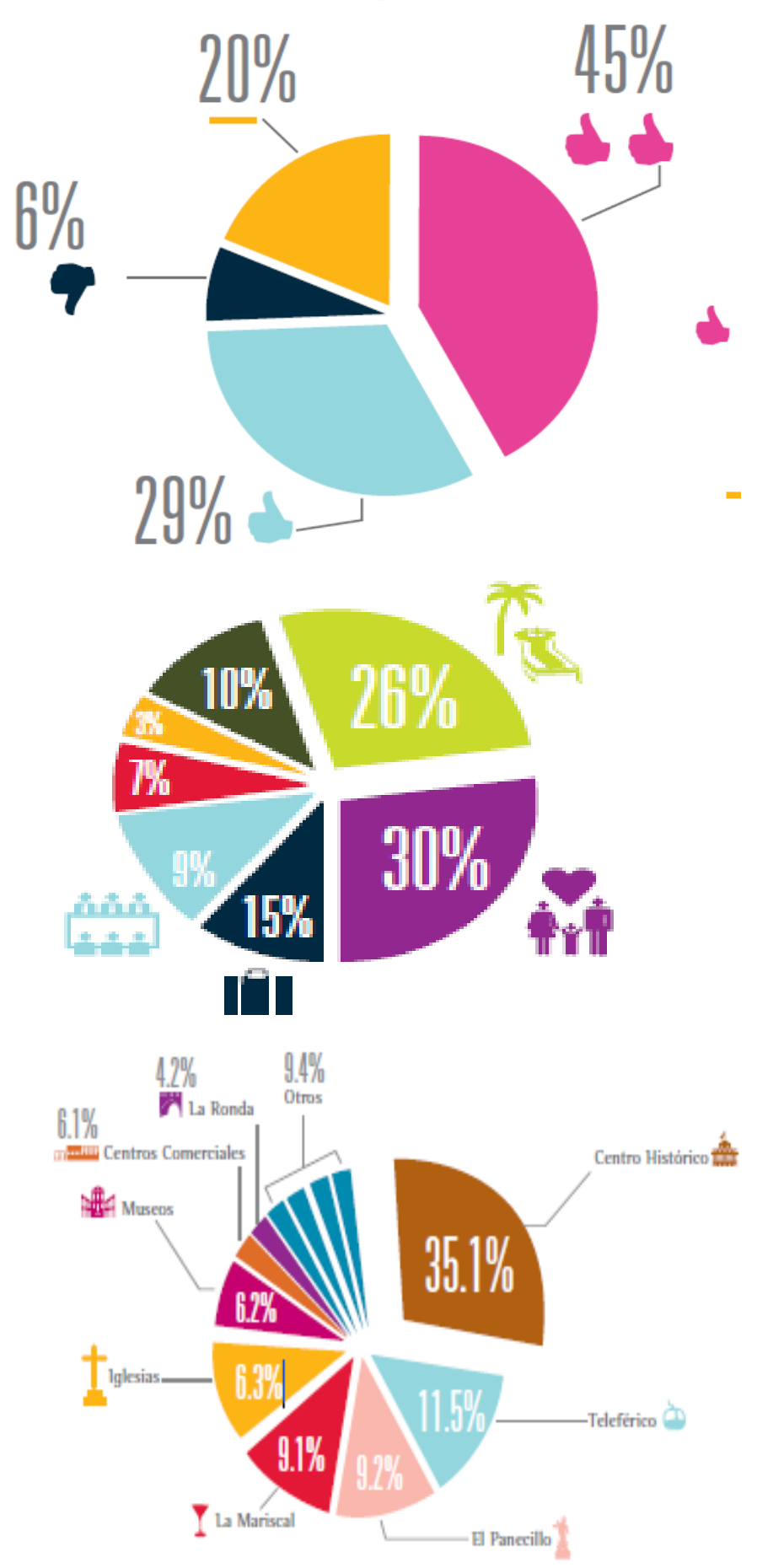

Fuente: Elaboración propia 


\section{Estudio de mercado emisor turístico}

Estudios han demostrado que el sector primario en el país está representado por la agricultura, ganadería, silvicultura y pesca que simbolizan a nivel nacional el $20.77 \%$ de 22 tipos de actividades reconocidas a nivel nacional, considerada esta como la segunda fuerza económica, donde su mayor representatividad está en la zona rural que figura el $48.4 \%$ del total de actividades del área. La segunda actividad más representativa resultó ser el comercio al por mayor y menor con un $17.61 \%$ a nivel de país reconociendo que el $28.8 \%$ de esta actividad se desempeña en la zona urbana del país. Por último, la tercera actividad económica está representada por las industrias manufactureras que figuran el $9.70 \%$ a nivel nacional donde el 10.56\% de estas están ubicada también en la zona urbana del país (REDATAM, 2017).

Las actividades de alojamiento y servicio de comidas a nivel nacional representan el 3.63\% de la totalidad de actividades, esta representa la décima actividad más significativa y la tercera fuente de ingreso económico del país. Dentro de las provincias costeras las más representativas por densidad poblacional y mayor representatividad de esta rama de actividad están ubicadas en las provincias de Guayaquil, Santa Elena, Manabí y Esmeraldas. En la figura 2 se representa el nivel de servicio de alojamiento en las provincias costera.

Figura 2. Nivel de representatividad de Actividad de alojamiento

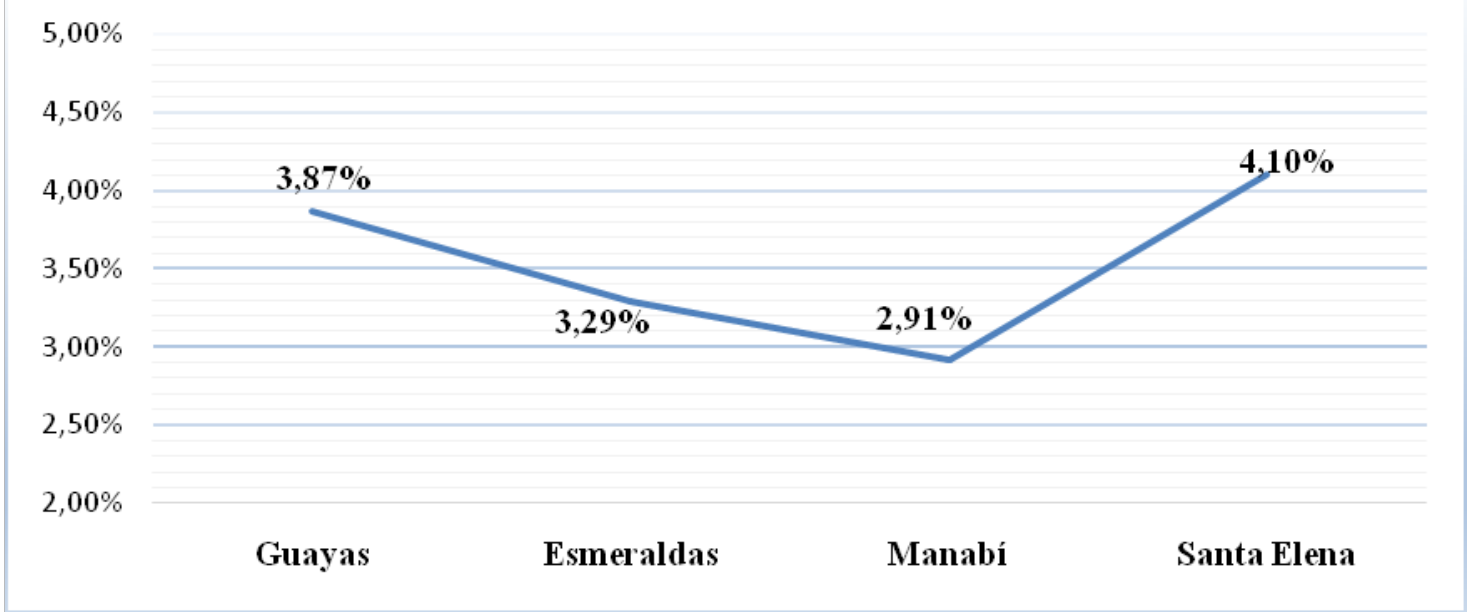

Fuente: Elaboración propia

Como se observa la más representativa es la provincia de Santa Elena seguida por la provincia de Guayas ambas ubicadas en el mismo litoral y continuas una de la otra geográficamente, en tercer puesto Esmeralda y en cuarto Manabí, todas con infraestructura de alojamiento propias de su entorno y actividad turística.

El sector comercial y de servicios genera aproximadamente el 37\% de ingresos por sus diversos atractivos y recursos turísticos existentes en las provincias anteriormente analizadas. El sector agrícola, ganadero, silvicultor y pesca siguen ocupando en tres cantones la primera actividad económica generadora de fuentes de ingresos y empleos, seguida por el comercio al por mayor y al por menor del total de actividades que se generan provincialmente. A continuación, se muestra en la figura 3 un estudio de participación del mercado a nivel de rama de actividad. 
Figura 3.Estudio de participación a nivel de actividad económica por provincias

Provincia

Guayas

Esmeraldas

Manabí

Santa Elena
Actividad Económica

Comercio al por mayor y menor
Agricultura, ganadería, silvicultura y pesca
Industrias manufactureras
Actividades de alojamiento y servicio de
comidas

Agricultura, ganadería, silvicultura y pesca

Comercio al por mayor y menor

Enseñanza

Actividades de alojamiento y servicio de comidas

$\begin{array}{cl}\text { Manabí } & \text { Agricultura, ganadería, silvicultura y pesca } \\ & \text { Comercio al por mayor y menor } \\ & \text { Industrias manufactureras } \\ & \text { Actividades de alojamiento y servicio de } \\ \text { comidas } & \text { Agricultura, ganadería, silvicultura y pesca } \\ \text { Santa Elena } & \text { Comercio al por mayor y menor } \\ & \text { Industrias manufactureras } \\ & \text { Actividades de alojamiento y servicio de } \\ & \text { comidas }\end{array}$

$22.43 \%$

$11.95 \%$

$9.58 \%$

$3.87 \%$

$28.68 \%$

$12.04 \%$

$5.75 \%$

$3.29 \%$

$27.63 \%$

$15.06 \%$

$7.39 \%$

$2.91 \%$

$17.84 \%$

$17.57 \%$

$9.61 \%$

$4.10 \%$

Participación en el mercado

Fuente: Elaboración propia

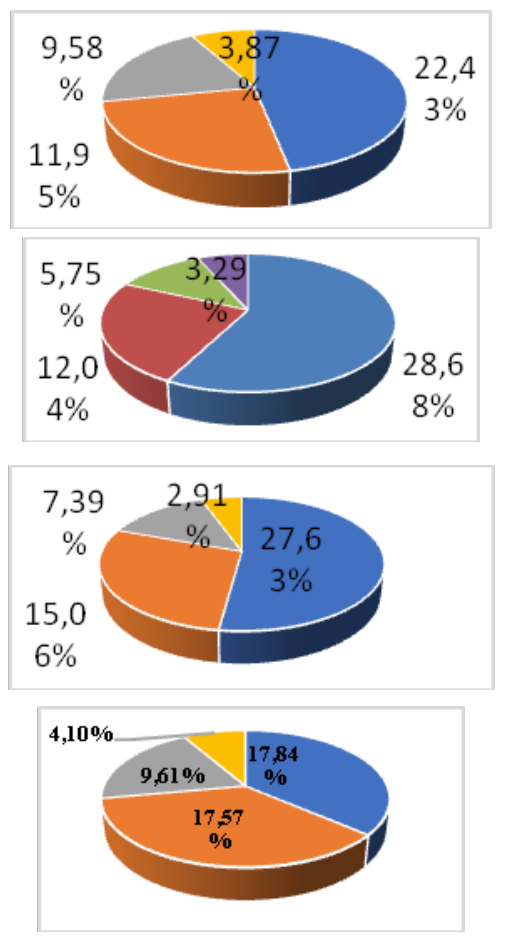

En el 2016 el país presento aproximadamente 4.500 establecimientos de alojamiento turístico, en la actualidad en la litoral costa de Manabí en los cantones Sucre, San Vicente, Jama y Pedernales ha existido un crecimiento de infraestructura hotelera de un 5.25\% para un total de 177 infraestructura más representativas son clasificadas como hotel, hostal, cabaña y hostería. Es importante reconocer según catastro existente en Observatorio Turístico de la Extensión que el cantón San Vicente representa el 35.03\% del total de infraestructura, seguido por el cantón Sucre que figura el $30.51 \%$, Pedernales con el $23.16 \%$ y por último Jama con $11.30 \%$ de representatividad de infraestructura de alojamiento.

Es importante considera las cifras de turistas que han ingresado al país con la finalidad de realizar una valoración que aporte al presente estudio. Tomando como año base el 2015 de los 14 países más representativos que ingresaron por concepto de turismo se recalca que dejaron de ingresar un total de 11.257 (miles) de turistas al país respecto al 2014, aunque se observa que países como Venezuela, Cuba, Perú y Colombia tienen un alto índice de representatividad en el país, estos considerados por cuestiones de emigración, trabajo e intercambio colaborativo (ver tabla 1). 
Tabla 1: Resultados históricos de ingreso por turistas

\begin{tabular}{ccccc}
\hline País & 2014 & 2015 & 2016 & 2017 \\
\hline Colombia & 368.079 & 348.151 & 318.868 & 335.724 \\
Cuba & 41.545 & 79.236 & 26.078 & 25.036 \\
Venezuela & 119.763 & 105.533 & 102.619 & 288.395 \\
USA & 259.406 & 263.081 & 266.989 & 244.672 \\
Canadá & 33.23 & 32.541 & 29.886 & 28.445 \\
Holanda (Países Bajos) & 15.444 & 15.481 & 16.992 & 15.926 \\
Perú & 175.405 & 165.223 & 147.601 & 139.861 \\
Argentina & 58.591 & 54.513 & 44.534 & 44.804 \\
Reino Unido & 27.126 & 26.782 & 28.908 & 25.866 \\
España & 67.623 & 67.545 & 62.984 & 58.903 \\
Alemania & 33.303 & 33.209 & 30.881 & 33.505 \\
Chile & 43.871 & 40.927 & 40.927 & 44.808 \\
Brasil & 21.772 & 20.629 & 19.119 & 21.964 \\
México & 27.974 & 27.104 & 26.925 & 27.585 \\
Otros & 263.859 & 264.779 & 254.848 & 282.419 \\
\hline Totales & 3570.991 & 3559.734 & 3434.159 & 3634.913
\end{tabular}

El comportamiento de los consumidores fue poco representativo en el año 2017, donde países como Reino Unido dejo de ingresar un $-18.46 \%$, USA un $-9.84 \%$ y Holanda con un $-16.03 \%$ turistas que no ingresaron al país, siendo estos los mercados metas donde se han direccionado los principales productos turísticos. Aunque otros países como Brasil, México, Alemania y Chile, mostraron un índice de crecimiento de hasta 50\% aproximadamente más que el año 2017, respecto al 2018 y 2019 las estadísticas mostraron un 5.1\% de crecimiento respectivamente.

Es importante resaltar que desde el año 2015 al 2019 los índices de presencia de turista internacionales han variado y han afectado la actividad turística en las diferentes regiones del país, principalmente en la zona costa por el evento telúrico del 16 de abril del 2016, donde el nivel de afectación de los servicios hoteleros representó aproximadamente el $75 \%$ de daños a nivel parcial y total. Cifras estadísticas demuestran los comportamientos vulnerables a los eventos de índole demográficos, sociales y políticos que han sucedido en esta etapa objeto estudio. En la tabla 2 se muestra el comportamiento de los turistas a nivel de país.

De la muestra encuestada para conocer el motivo que impulso a los turista visitar el destino, se utilizaron varias variables para medir el motivo de la visita de los turista a la playa observando que el más significativo fue el de visita a familia o amigos que represento un 32,5\% seguido del cultural que mide las actividades festivas que se realizan en el país, en este indicador están los feriados y carnavales que es donde mayor movilidad de visitante llegan que figuro un $30 \%$ y en tercer lugar que también estuvo significativo fue el de descanso y placer con un $25 \%$, los demás parámetros evaluados estuvieron por debajo del $10 \%$ por lo que es representativo para tenerlo en cuenta en el estudio. 
Tabla 2: Estudio comparativo de entrada de turistas

\begin{tabular}{cccc}
\hline País & $\mathbf{2 0 1 5 / 2 0 1 4}$ & $\mathbf{2 0 1 6 / 2 0 1 5}$ & $\mathbf{2 0 1 7 / 2 0 1 6}$ \\
\hline Colombia & -19.928 & -29.283 & 16.856 \\
Cuba & 37.691 & -53.158 & -1.042 \\
Venezuela & -14.23 & -2.914 & 185.776 \\
USA & 3.675 & 3.908 & -22.317 \\
Canadá & -0.689 & -2.655 & -1.441 \\
Holanda (Países Bajos) & 0.037 & 1.511 & -1.066 \\
Perú & -10.182 & -17.622 & -7.74 \\
Argentina & -4.078 & -9.979 & 0.27 \\
Reino Unido & -0.344 & 2.126 & -3.042 \\
España & -0.078 & -4.561 & -4.081 \\
Alemania & -0.094 & -2.328 & 2.624 \\
Chile & -2.944 & 0 & 3.881 \\
Brasil & -1.143 & -1.51 & 2.845 \\
México & -0.87 & -0.179 & 0.66 \\
Otros & 0.92 & -9.931 & 27.571 \\
\hline Totales & -11.257 & -125.575 & 200.754 \\
\hline
\end{tabular}

Fuente: Elaboración propia

Otro indicador que arrojo resultado tentativo estuvo relacionado con los medios de comunicación que emplearon para conocer del destino, donde el $48 \%$ de los turistas conocieron el destino a través de recomendaciones de familiares y amigos, otro 33,8\% de visitantes conocen al destino por medio de las redes sociales y sitios de internet y solo el 11,3 \% de los consumidores fue a través de agencia de viajes. Lo que denota que existe un número representativo de visitantes al destino.

Una encuesta aplicada a visitantes en el feriado de carnaval del 2018, cuya muestra fue aleatoria simple debido a estimaciones de pronósticos de visitantes realizado con años anteriores, cuya población seleccionado fue el sector costa del país por el número de afluencia de turistas en estas temporadas. La temática del instrumento fue referente a la seguridad turística, debido algunos eventos negativos que en años anteriores se había desarrollado, además de perdida de la imagen del destino. Los resultados más representativos para conocer los niveles de aceptación o satisfacción se seleccionaron los siguientes elementos: Hospedaje, servicios gastronómicos y diversión.

El servicio de hospedaje fue evaluado de regular representando el 57,5\% de los encuestados, mientras que el servicio de gastronómico o comidas típicas 42,5 \% la evaluó de excelente y el $42,5 \%$ la apreció de buena denotando que el nivel de aceptación de este indicador es muy bueno por lo que es uno de los atractivos del visitante, donde solo un 12,5\% lo califico de regular. Del servicio de diversión fue valorado de bueno con un $41,3 \%$ y un $28,8 \%$ lo categorizo de regular denotando que hay que buscar alternativas o estrategias para hacerlo más atractivo al turista.

La seguridad turística otra variable de medición fue definida como la protección de la vida, de la salud, de la integridad física, psicológica y económica de los visitantes, prestadores de servicios 
y miembros de las comunidades receptoras. Estos servicios se evaluaron de malo con el 62,5\% de los encuestados y el 32,5\% respondió que estos servicios eran regulares, representativo el $73,8 \%$ confirmo que no existe una seguridad sobre sus pertinencias y de sus permanencia denotando la inconformidad de los turista por su seguridad. Se indica que por su relevancia se deben trazar estrategias funcionales que mejoren la seguridad de su estancia en esta playa.

En la tabla 3. se refleja los resultados referentes a las opciones que los servicios de seguridad que más distintivo representan para mantener la disciplina de los bañista en la playa siendo la más representativa la presencia de policías o guardias de playas que represento un $55 \%$, seguido de salvavidas con un $22,5 \%$ que es de vital importancia para garantizar la supervivencia de los bañistas, con un 11,3\% de taquilleros públicos que disminuirían los índices delictivos y con un $10 \%$ la presencia de para médicos.

Tabla 3: Opciones de seguridad turística

\begin{tabular}{cccccc}
\hline & & Frecuencia & Porcentaje & Porcentaje válido & $\begin{array}{c}\text { Porcentaje } \\
\text { acumulado }\end{array}$ \\
\hline \multirow{4}{*}{ Válidos } & Guardias o Policías & 44 & 55,0 & 55,0 & 55,0 \\
& Salvavidas & 18 & 22,5 & 22,5 & 77,5 \\
& Taquilleros Públicos & 9 & 11,3 & 11,3 & 88,8 \\
& Para Médicos & 8 & 10,0 & 10,0 & 98,8 \\
& otros & 1 & 1,3 & 1,3 & 100,0 \\
\cline { 2 - 5 } & Total & 80 & 100,0 & 100,0 & \\
\hline
\end{tabular}

Fuente: Elaboración propia

\section{Análisis de las contradicciones sociales}

Las contradicciones sociales son dadas en un destino turístico por todas las fuerzas actuantes que indicen en el entorno del destino. Considerando que las actividades económicas forman parte de que a nivel social existan contradicciones propias ocasionadas por las leyes y políticas vigentes sin ignorar los gobiernos en turno. Por lo que se hace importante además la existencia de una relación significativa de los atributos de responsabilidad social empresarial (RSE) donde no solo influyen estos factores del entorno sino lo concerniente al recurso humano y de algunas de las competencias corporativas (CC) dependiendo del sector económico sobre el comportamiento de compra del consumidor. También se hace evidente considerar a los consumidores que están dispuestos a pagar una mayor proporción del precio del producto por atributos empresariales vinculados a la responsabilidad social (Feldman \& Reficco, 2015).

Valorar las contradicciones sociales como un elemento que aporta a un comportamiento no favorable del consumidor es importante, debido a que esto puede incidir negativamente en las ofertas y las demandas de los consumidores, además de degradar la imagen de un destino y conllevar a desestabilizar la actividad turística en el país, por lo que desde la óptica positivista se realiza un enfoque de ver estas contradicciones sociales como un factor estratégico para fortalecer y posicionar la actividad turística en un mercado internacionales factibles. 
En el proceso de evaluación del comportamiento del consumidor a partir de estudios estadísticos reflejado anteriormente, de la aplicación de encuestas y fundamentaciones de teóricos relacionado con el estudio permiten argumentar sobre la gestión de destinos en el Ecuador o sectores del país que se han escogido para referenciar en este estudio, donde se manifiestan las siguientes contradicciones mostrada en la tabla 4.

\section{Conclusiones}

Las fuentes bibliográficas consultadas aportaron a verificar a los consumidores turísticos de acuerdo a los factores socioculturales propios del destino desde la particularidad de adoptar un enfoque integrado, que tenga en cuenta las dimensiones económica, social y ambiental para lograr una gestión comercial de destinos turísticos sostenible.

El estudio realizado a nivel de rama de actividad permitió desarrollar una valoración de lo que estas personifican a nivel económico en el país y a nivel del sector de alojamiento otorgándole desde el criterio calificativo que las presuntas atenuantes sociales existentes por determinado factor del entorno pueden considerarse como estrategias para reactivar la actividad turística a nivel de país, provincia y cantón.

Los análisis realizados de las contradicciones sociales a partir de los tipos de contradicciones y las especificaciones de las misma permitieron determinar las estrategias pertinentes para lograr un destino consolidado y sostenible, donde se reflexiona referente a la tipología de los consumidores considerándola no estática, debido a que cada sujeto puede variar su conducta dependiendo del entorno o momento en el cual se encuentren demostrado estadísticamente con niveles de satisfacción del destino aceptables.

\section{Referencias}

Campón A. (2009). Marketing Relacional en el Sector Turístico: la Fidelización de Clientes en el Turismo Rural. Recuperado https://ubibliorum.ubi.pt/bitstream/10400.6/3419/1/Marketing\%20Relacional\%20en\%20el\%20Sector\%20Tur\% C3\%ADstico\%2C\%20la\%20Fidelizaci\%C3\%B3n\%20de\%20Clientes\%20en\%20el\%20Turismo\%20Rural.pdf

Carbache Mora, C., Zambrano Zambrano, J., \& Lemoine Quintero, F. (2020). Estrategia de marketing emocional para la promoción de locales de servicios gastronómicos en la ciudad de Bahía de Caráquez. Ecuador. ECONÓMICAS CUC, 41(1), 203-216. https://doi.org/10.17981/econcuc.41.1.2020.Org.4

Carvajal, G. V., Valls, W., Lemoine, F. Á., \& Alcívar, V. E. (2017). Gestión por procesos: Un principio de la gestión de calidad. Manta, Manabí, Ecuador: Editorial Mar Abierto.

Feldman, P. M., \& Reficco, E. (2015). Impacto de la responsabilidad social empresarial en el comportamiento de compra y disposición a pagar de consumidores bogotanos. Estudios Gerenciales (31). 373-382. http://dx.doi.org/10.1016/j.estger.2015.10.001,

Gould, F. J., G. D. Eppen et al. (1993). Investigación de operaciones en la ciencia administrativa, México: Editora Prentice Hall Inc., México.

Paul Peter, J. \& Olson, J. (2006). Comportamiento del consumidor y estrategia de marketing. México: McGraw-Hill Interamericana Editores S.A. de C.V.

IPSA SCIENTIA - Vol. 5 No $1-2020$ 
Kotler, P. \& Armstrong G. (2008). Fundamentos de marketing. Octava edición. México: PEARSON EDUCACIÓN.

Kotler, P. K., \& Armstrong, G. (2007). Marketing: Versión para Latinoamérica. Decimoprimera edición. México: Pearson Education.

Kotler, P., \& Armstrong, G. (2012). Marketing. Decimocuarta edición. México: Pearson Education.

Lavidge, R.J. (1970). The Growning responsabilities Of Marketing. Journal of Marketing, 34(III). 27. https://doi.org/10.1177\%2F002224297003400108

Lemoine, Á., Reyes, I. A., \& Valls, W. (2019). Sostenibilidad de los servicios hoteleros en su entorno sociocultural. Bahía de Caráquez, Ecuador 2017. Revista de Ocio y Turismo, 13(1), 40-50. https://doi.org/10.17979/rotur.2019.13.1.3470

Lemoine, F. À. (2018). Metódica para medir comportamientos de los consumidores en el sector hotelero. Ecuador. Revista Argentina de Investigación en Negocios, 4(1), 115-121.

Lemoine, F. À., Carvajal, G., Zamora, M. A., \& Castellanos, G. (2018). La imagen comercial y su influencia socio económica empresarial de los pequeños negocios del cantón Sucre. Ecuador. INNOVA ResearchJournal, 3(2), 99-112. https://doi.org/10.33890/innova.v3.n2.2018.417

Lemoine, F. Á., Delgado, K. E., Carvajal, G. V., \& Alcívar, V. E. (2017). La percepción sobre sustentabilidad del turismo en el cantón San Vicente. Revista Magazine de las Ciencias,2(2), 23-38.

Lemoine, F. Á., Villacís, L. M., Hernández, N. R., Zamora, Y. A., \& Montesdeoca, M. G. (2019). Gestión del marketing turístico sostenible. Manta: Editorial Universitaria, Ediciones Uleam.

Mármol, P. \& Ojeda, C. (2016). Marketing turístico 2. edición. España: Editorial Paraninfo.

MINTUR. (2017). Anuario de Estadística Turística. Recuperado de http://servicios.turismo.gob.ec/index.php/anuario-de-estadisticas-turisticas

MINTUR. (2018). Ecuador ama la vida. Recuperado de: http://servicios.turismo.gob.ec/index.php/54-turismo-encifras/estadisticas-locales-de-turismo/281-sistema-de-estadisticas-locales-de-turismo-sostenible

OMT. (1994). Recuperado de: http://ponce.inter.edu/cai/tesis/alotti/cap2.htm.

Ramírez, D-E., Otero, M-C., \& Giraldo, W. (2014). Comportamiento del consumidor turístico. Criterio Libre. 12(20), 165-183.

REDATAM. (2017). Sistema Integrado de Consultas. Ecuador. Recuperado de http://www.ecuadorencifras.gob.ec/sistema-integrado-de-consultas-redatam/

Rodríguez E. (2011). Evolución histórica del turismo. Recuperado de: https://es.slideshare.net/fonsecamariele/elturismo-y-su-evolucion-54547671

Spencer, H. \& Moinpour R. (1972). Market orientation and the learning organization. Journal of Marketing, Chicago, 59(3). 63-74.

Valls, W., \& Lemoine, F. Á. (2018). El enfoque de sistema, piedra angular para una gestión investigativa efectiva. Caso Bahía de Caráquez. Revista científica electrónica de Educación y Comunicación en la Sociedad del Conocimiento, 1(18). 398-414. 
Tabla 4: Contradicciones sociales para gestionar un destino integral

\begin{tabular}{|c|c|c|}
\hline Tipos de contradicciones & Especificaciones & Estrategias \\
\hline Contradicciones Epistemológicas & $\begin{array}{l}\text { A partir de consultas bibliográficas se fundamenta reconocer } \\
\text { cambios constantes en el comportamiento del consumidor por } \\
\text { los resultados arrojados de modelos de comportamientos, } \\
\text { herramientas y métodos y técnicas de marketing para la } \\
\text { gestión comercial de un destino turístico. }\end{array}$ & $\begin{array}{l}\text { 1. Estrategias de enfoque integrado de las } \\
\text { dimensiones de la realidad social } \\
\text { 2. Estrategias efectivas metodológica de las } \\
\text { evaluaciones del comportamiento de los } \\
\text { turistas y su dinámica actual }\end{array}$ \\
\hline Contradicciones Políticas & $\begin{array}{l}\text { El cambio o transformación de la matriz Productiva y el Plan } \\
\text { del Buen Vivir que van dirigido a las clases sociales más } \\
\text { desfavorecida del país y a fortalecer la producción nacional, } \\
\text { aunque los gobiernos en turno no cumplen con las leyes } \\
\text { vigentes establecidas. }\end{array}$ & $\begin{array}{l}\text { 1. Estrategias de alianzas entre sectores públicos } \\
\text { y privados para fortalecer la actividad } \\
\text { turística y su gestión como eslabón primordial } \\
\text { para el desarrollo y estabilidad económica del } \\
\text { país. }\end{array}$ \\
\hline Contradicciones Económicas & $\begin{array}{l}\text { El desarrollo económico propio del país requiere que las } \\
\text { decisiones propias del sector turístico sean canalizadas } \\
\text { ordenadamente y equilibradamente, donde estas a su vez } \\
\text { contribuyan al bienestar de población y al cumplimento de los } \\
\text { objetivos de las políticas y leyes vigentes del MINTUR }\end{array}$ & $\begin{array}{l}\text { 1. Control sistemático de los niveles de } \\
\text { satisfacción del turista } \\
\text { 2. Evaluar la interacción residente-turista como } \\
\text { un componente importante en la experiencia } \\
\text { turística en el destino } \\
\text { 3. Desarrollar campañas función de la } \\
\text { publicidad para promocionar las actividades } \\
\text { turísticas a nivel de país y a nivel de destino }\end{array}$ \\
\hline Contradicciones Culturales & $\begin{array}{l}\text { La autoidentificación según cultura y costumbres identifican } \\
\text { la interculturalidad en el país, por lo que se debe de considerar } \\
\text { esta como un elemento fundamental para gestionar destino } \\
\text { efectivo }\end{array}$ & $\begin{array}{l}\text { 1. Fortalecimiento integral que tribute al } \\
\text { elemento identitario constructor de la unidad } \\
\text { de la nación y factor de innovación } \\
\text { tecnológica y de sustentabilidad de la } \\
\text { actividad turística en le región. } \\
\text { 2. Estrategia de implementación de modelo de } \\
\text { calidad de servicios integrales }\end{array}$ \\
\hline Contradicciones Ambientales & $\begin{array}{l}\text { Contribución a los elementos que integran el desarrollo } \\
\text { sustentable a través del emprendimiento sostenible y la } \\
\text { responsabilidad social }\end{array}$ & $\begin{array}{l}\text { 1. Estrategias sostenibles de impactos } \\
\text { ambientales - ecológicos. } \\
\text { 2. Estrategias de conservación de los recursos } \\
\text { naturales y de preservación de la } \\
\text { biodiversidad. }\end{array}$ \\
\hline
\end{tabular}

Fuente: Elaboración propia 